\title{
High mobility group AT-hook 2 and c-MYC as potential prognostic factors in pancreatic ductal adenocarcinoma
}

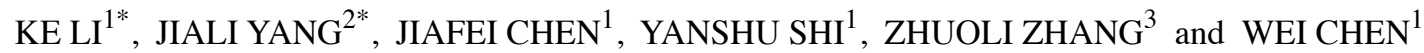 \\ ${ }^{1}$ Department of Radiology and ${ }^{2}$ Institute of Hepatopancreatobiliary Surgery, First Affiliated Hospital, \\ Army Medical University, Chongqing 400038, P.R. China; ${ }^{3}$ Northwestern Quantitative Imaging Core Lab, \\ Feinberg School of Medicine, Northwestern University, Chicago, IL 60611, USA
}

Received June 6, 2019; Accepted November 8, 2019

DOI: $10.3892 / \mathrm{ol} .2019 .11205$

\begin{abstract}
The present study investigated if c-MYC and high mobility group AT-hook 2 (HMGA2) expression was associated with prognosis of patients with pancreatic ductal adenocarcinoma (PDAC). A total of 102 patients undergoing surgery for PDAC were retrospectively reviewed. Immunohistochemistry was used to detect c-MYC and HMGA2 protein expression in PDAC and peritumoral tissue samples. Expression of c-MYC and HMGA2 was associated with clinicopathological characteristics and prognoses of patients with PDAC using multivariate analysis. HMGA2 and c-MYC protein expression was significantly higher in PDAC tissues compared with peritumoral tissue $(\mathrm{P}<0.001)$. HMGA2 and c-MYC expression was also significantly higher in patients with PDAC who had lymph node metastasis, invasion of regional tissues and tumor node metastasis (TNM) stage III or IV disease compared with those who had no lymph node metastasis, no invasion of regional tissues and TNM stage I or II disease $(\mathrm{P}<0.001)$. Multivariate logistic regression analysis was used to identify TNM stage $(\mathrm{P}=0.007)$ and invasion $(\mathrm{P}=0.003)$ as significant independent predictors of $\mathrm{c}-\mathrm{MYC}$ expression (model AUC $=0.8201$ ), and lymph node metastasis $(\mathrm{P}=0.002)$ and invasion $(\mathrm{P}=0.003)$ as significant independent predictors of HMGA2 expression (model AUC $=0.7638$ ). Cox multivariate analysis showed that expression of c-MYC $(\mathrm{P}=0.019)$ and HMGA2 $(\mathrm{P}<0.001)$, TNM stage $(\mathrm{P}=0.014)$ and lymph node metastasis $(\mathrm{P}=0.032)$ were associated with reduced overall survival time. HMGA2 and c-MYC may be important biological markers and potential therapeutic targets involved in the tumorigenesis, metastasis, invasion and prognosis of PDAC.
\end{abstract}

Correspondence to: Dr Wei Chen, Department of Radiology, First Affiliated Hospital, Army Medical University, 30 Gaotanyan Street, Chongqing 400038, P.R. China

E-mail: landcw@hotmail.com

*Contributed equally

Key words: pancreatic ductal adenocarcinoma, immunohistochemistry, c-MYC, high mobility group AT-hook 2

\section{Introduction}

Pancreatic ductal adenocarcinoma (PDAC) is the most common type of malignant pancreatic tumor and is the fourth leading cause of cancer-associated mortality worldwide in 2014 (1-3). Surgical resection remains the only optimal treatment regimen for patients with PDAC (4). Due to the paucity of symptoms in the early stages, most PDACs are diagnosed at advanced stages, resulting in low resectability $(5,6)$. PDAC has a high recurrence rate, even in the small number of patients who undergo surgery, as it easily invades blood vessels and lymphatic tissue and has a tendency to disseminate along nerve fibers (7). In addition, PDAC produces dense desmoplastic stroma that consists of activated pancreatic stellate cells (PSCs) and proliferating fibroblasts surrounding the tumor cells which inhibits drug penetration and uptake (8-12). Currently, the overall survival (OS) time for patients with PDAC is $\sim 1$ year and the 5 -year OS rate is $<1.0 \%(13,14)$. The OS rate of patients with PDAC has not improved significantly despite intense research efforts being made to develop chemotherapy, radiotherapy and patient-targeted therapeutic strategies in recent years (15-17). There is an urgent need to find reliable prognostic biomarkers and new targets for future treatment.

c-MYC is one of the most frequently deregulated oncogenes and is located on the long arm of chromosome 8 (8q24), which encodes for the c-MYC protein, an important transcription factor involved in the regulation of protein synthesis, cellular metabolism and tumor growth and proliferation (18-20). Previous studies have demonstrated that abnormal expression of c-MYC is implicated in many malignancies such as Burkett's lymphoma, diffuse large B-cell lymphoma and breast cancer $(21,22)$, c-MYC upregulation is frequently associated with poor clinical outcome (23). There have also been a few reports related to $\mathrm{PDAC}(18,24)$.

The high mobility group AT-hook 2 (HMGA2) protein is encoded by the HMGA2 gene, and is a member of the high mobility group (HMG) protein family and non-histone chromatin-binding protein family $(25,26)$. HMGA2 protein has a DNA-binding domain located in the N-terminal region and three short basic repeats, the so-called AT-hooks, which bind to the minor groove of AT-rich DNA sequences $(27,28)$. Once bound to DNA, HMGA2 interacts with various transcription factors to modulate gene transcription and alter 
chromatin structure, regulate cell growth, differentiation, apoptosis and DNA repair $(29,30)$. HMGA2 protein is highly expressed during embryonic development and is expressed at low levels in adult tissues $(26,31)$. High expression of HMGA2 has been detected in most human malignancies, including colorectal cancer, Wilms' tumor and PDAC, and is associated with higher lymph node metastasis rates and poor tumor differentiation (32-34).

To date, no systematic study has investigated the relationship between the expression of HMGA2 and c-MYC and PDAC. In the present study, the expression of c-MYC and HMGA2 in resected specimens, including adenocarcinoma and peritumoral tissue, was examined using immunohistochemistry. The association of c-MYC and HMGA2 levels with the prognosis of PDAC was evaluated. This study suggests that c-MYC and HMGA2 are promising prognostic biomarkers and potential therapeutic targets in PDAC.

\section{Materials and methods}

Case selection. A total of a 102 PDAC and 93 peritumoral tissues were obtained at the First Affiliated Hospital, Army Medical University (Chongqing, China) between March 2013 and September 2015. This study was pre-approved by the Ethics Committee for Human Study of Army Medical University (approval no. KY201802) and oral consent was previously obtained from the family members of the patients included in the study. The ethics committee waived the requirement for further written informed consent for this study. Clinical information collected included: Gender, age, tumor location, tumor size, degree of tumor differentiation, tumor staging, regional lymph node metastasis, invasion to surrounding organs and serum CA19-9 level. Tumor staging, regional lymph node metastasis, invasion and serum cancer antigen (CA) 19-9 level were based on the 8th edition American Joint Committee on Cancer (AJCC) standard criteria $(35,36)$. Survival information was obtained through letters and phone calls from patients with PDAC. Peritumoral tissue $(n=93)$ was collected $\geq 2 \mathrm{~cm}$ from the tumors. A flowchart of the process is presented in Fig. 1.

Immunohistochemistry. All tissues were treated with $10 \%$ formaldehyde for $24-48 \mathrm{~h}$ at room temperature, and embedded in paraffin. For immunohistochemistry, $3-\mu \mathrm{m}$ thick sections were mounted on poly-L-lysine-coated slides, deparaffinized with xylene three times for $5 \mathrm{~min}$, and hydrated through graded alcohols to water. Endogenous peroxidase activity was inhibited by dipping sections in $3 \%$ hydrogen peroxide for $10 \mathrm{~min}$ at room temperature. This was followed by incubation with primary antibodies against c-MYC and HMGA 2 at $4{ }^{\circ} \mathrm{C}$ overnight (diluted 1:200; cat. nos. 10828-1-AP and 20795-1-AP, respectively; ProteinTech Group, Inc.). Subsequently, the sections were washed with three changes of PBS for $15 \mathrm{~min}$ and incubated with horseradish peroxidase-conjugated goat anti-mouse/rabbit IgG compound (1:50; cat. no. KIT-9903; Fuzhou Maixin Biotech Co., Ltd) for $1 \mathrm{~h}$ at room temperature. Following three washes with PBS for $15 \mathrm{~min}$, the sections were incubated with DAB solution (Beyotime Institute of Biotechnology) for $10 \mathrm{~min}$ at room temperature. Finally, samples were counterstained with hematoxylin (Beyotime
Institute of Biotechnology) for $2 \mathrm{~min}$ at room temperature. A total of 500 cells from 10 random fields per section were examined by 2 independent observers. The mean of the percentages from these 2 observers was used for final evaluation. Cases with $\geq 25 \%$ positive cells were considered positive, whereas other cases were considered negative (positive controls were provided by Protein Tech Group, Inc.) (37). Results were visualized using an Olympus light microscope (Olympus Corporation) at x400 magnification.

Statistical analysis. All data were analyzed with SPSS 18.0 (SPSS, Inc.). Continuous variables were summarized as mean \pm standard deviation (SD) and the categorical variables were described as percentage. Protein expression of c-MYC and HMGA2 was compared between PDAC and peritumoral tissue samples using McNemar's test. The association of c-MYC and HMGA2 expression with histological or clinical factors was analyzed using the $\chi^{2}$ test. The correlation between c-myc and HMGA2 expression was tested by the contingency coefficient test. Multiple logistic regression analysis was subsequently used to determine the association between histological or clinical factors and c-MYC and HMGA2 protein expression. In multivariate logistic regression analysis, factors with $\mathrm{P}<0.15$ in the univariate model were entered into the initial model. The backward elimination method was used to select the final predictive model. At each step, factors with $\mathrm{P}>0.05$ were eliminated. A receiver operating characteristic curve for the model was constructed and the area under the curve (AUC) was calculated. The OS of patients with PDAC was analyzed using Kaplan-Meier univariate survival analysis and log-rank tests. Multivariate analysis was performed with Cox proportional hazards model and $95 \%$ confidence intervals (CI) were calculated. $\mathrm{P}<0.05$ was considered to indicate a statistically significant difference.

\section{Results}

Characteristics of the study population. The 102 PDAC specimens were obtained from 58 males (56.9\%) and 44 females $(43.1 \%)$, with a mean age of $53.20 \pm 9.96$ years. Preoperative computerized tomography (CT) imaging showed that 62 PDACs $(60.8 \%)$ were located at the head of the pancreas and $40(39.2 \%)$ at the body or tail of the pancreas. The diameter of the lesions was $\leq 3 \mathrm{~cm}$ in 21 cases (20.6\%), $3-5 \mathrm{~cm}$ in 55 cases (53.9\%) and $>5 \mathrm{~cm}$ in 26 cases. The histopathological subtypes included 67 poorly-differentiated adenocarcinomas (65.7\%), 35 moderately-differentiated adenocarcinomas (34.3\%) and 0 well-differentiated adenocarcinomas. Of the cases, 58 (56.9\%) were stage $\mathrm{T} 1+\mathrm{T} 2$ and $44(43.1 \%)$ were stage $\mathrm{T} 3+\mathrm{T} 4$. Of the patients, $43(42.2 \%)$ had regional lymph node metastasis, $53(52.0 \%)$ had invasion to surrounding organs and tissues and 72 (70.6\%) had serum CA19-9 level $>37$ U/ml (Table I).

Protein expression of c-MYC and HMGA2 in PDAC and peritumoral tissues. Representative preoperative CT images of PDAC and immunohistochemical staining of tissues are presented in Fig. 2. Only 93 paired PDAC and peritumoral tissue were included. Of the PDAC tissues, $50(53.8 \%)$ were c-MYC positive and 47 (50.5\%) were HMGA2 positive. Of the peritumoral tissue, 23 (24.7\%) were c-MYC positive and 


\section{All patients primarily diagnosed with PDAC between March} 2013 and September 2015 were eligible $: \mathrm{N}=149$

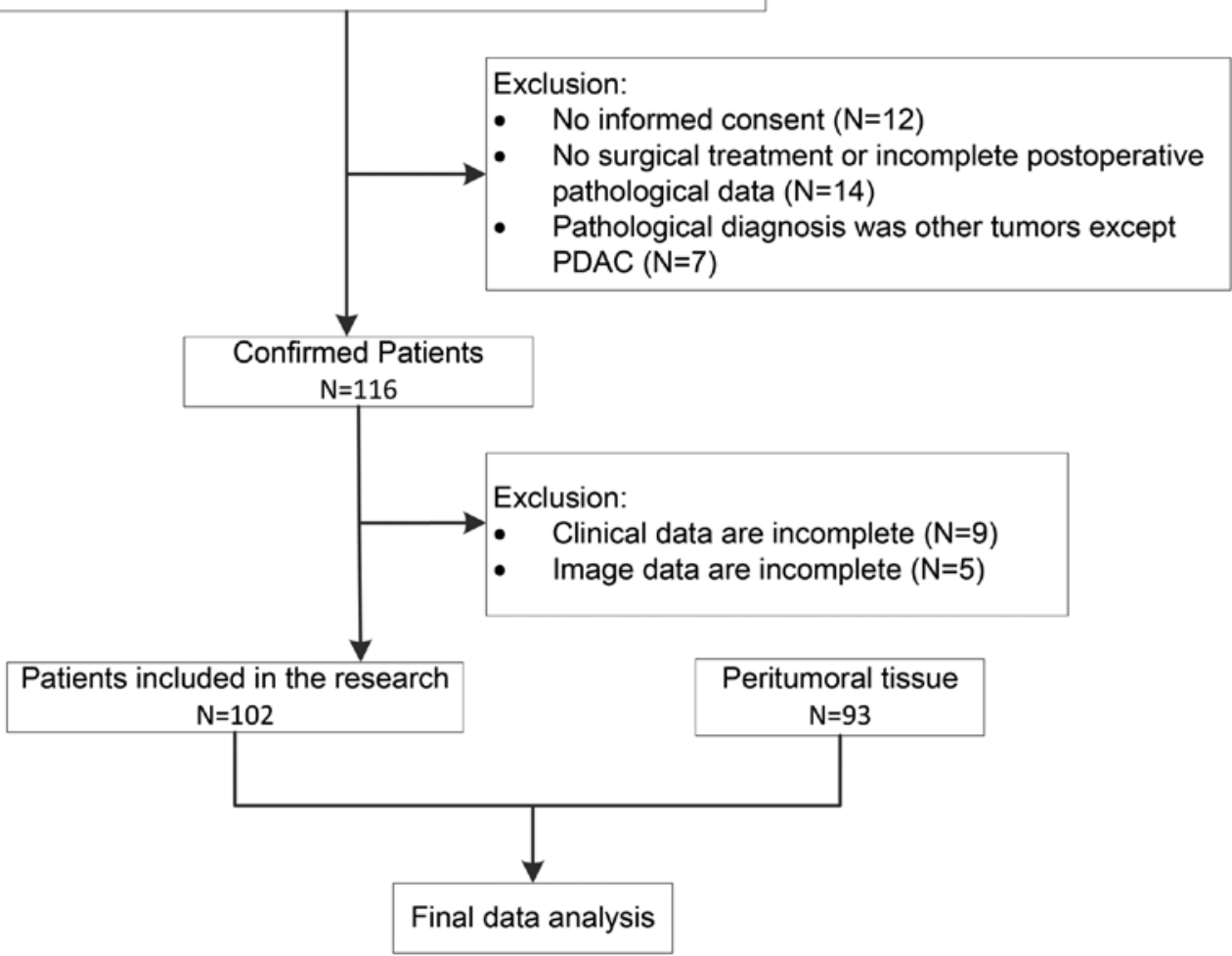

Figure 1. Flowchart of the process for inclusion and exclusion of patients with PDAC. PDAC, pancreatic ductal adenocarcinoma.

$25(26.9 \%)$ were HMGA2 positive. The positive rates for c-MYC and HMGA2 protein expression were significantly higher in PDAC tissue samples compared with peritumoral tissue samples $(\mathrm{P}<0.001$, respectively; Fig. $3 \mathrm{~A})$.

Association of c-MYC and HMGA2 protein expression with clinicopathological characteristics of patients with PDAC. The protein expression of c-MYC and HMGA2 exhibited no significant association with age, sex, tumor differentiation, size and location and serum CA19-9 level ( $\mathrm{P}>0.05$; Table II). The positive rate of $\mathrm{c}-\mathrm{MYC}$ and HMGA2 expression was significantly higher in PDAC patients with lymph node metastasis, invasion to surrounding tissues and organs and TNM stage III or IV disease compared with PDAC patients with no lymph node metastasis, no invasion, and TNM stage I and II disease $(\mathrm{P} \leq 0.001$; Table I). Expression of c-MYC was positively correlated with HMGA2 (the contingency coefficient is $0.210, \mathrm{P}=0.030)$. Multivariate logistic regression analysis revealed that TNM stage [odds ratio (OR), 5.097; 95\% CI, 1.546-16.805; $\mathrm{P}=0.007]$ and invasion $(\mathrm{OR}, 5.249 ; 95 \% \mathrm{CI}$, 1.734-15.886; $\mathrm{P}=0.003$ ) were predictors of $\mathrm{c}-\mathrm{MYC}$ protein expression. The AUC was 0.8201 (95\% CI, 0.7345-0.9056; $\mathrm{P}<0.0001$; Table II; Fig. 3B). Lymph node metastasis (OR, 4.147; 95\% CI, 1.653-10.407; $\mathrm{P}=0.002)$ and invasion (OR, $3.811 ; 95 \% \mathrm{CI}, 1.556-9.336 ; \mathrm{P}=0.003)$ were predictors of HMGA2 protein expression compared with no lymph node metastasis and no invasion. The AUC for predicting HMGA2 expression was 0.7638 (95\% CI, 0.6705-0.8572; $\mathrm{P}<0.0001$; Table II; Fig. 3C).
HMGA2 and c-MYC protein expression and clinicopathological characteristics associated with $O S$ in patients with PDAC. OS time ranged from 1-30 months, with a mean of $9.86 \pm 7.99$ months. Kaplan-Meier survival analysis revealed that lymph node metastasis, TNM stage, tumor invasion, c-MYC and HMGA2 protein expression were significantly associated with reduced OS time of patients with PDAC $(\mathrm{P}<0.01$; Table III). The mean OS time for $\mathrm{c}-\mathrm{MYC}$ or HMGA2-positive patients was significantly lower than for c-MYC or HMGA2-negative patients $(\mathrm{P}<0.01$; Fig. 3D-F). Cox multivariate showed that with stepwise regression analysis, TNM stage, lymph node metastasis, and C-MYC and HMGA2 protein expression finally entered the model. TNM stages III or IV, lymph node metastasis, c-MYC and HMGA2 protein high expression were negatively associated with the mean OS time (Table IV).

\section{Discussion}

PDAC remains a major therapeutic challenge with a poor prognosis due to a limited understanding of the molecular and genetic mechanisms and the potential therapeutic targets of PDAC. Though some targets have been investigated, no effective treatment for PDAC has been discovered. A previous study investigated the interaction of PDAC with its microenvironment. The stroma surrounding the tumor and its cellular components, PSCs, provides a protumorigenic microenvironment associated with tumor hypoxia, hypovascularization and epithelial-mesenchymal transition (8). The 
Table I. Association of c-MYC and HMGA2 protein expression with clinicopathological characteristics of pancreatic ductal adenocarcinoma.

\begin{tabular}{|c|c|c|c|c|c|c|c|c|c|}
\hline \multirow[b]{2}{*}{ Variable } & \multirow[b]{2}{*}{$\begin{array}{c}\text { Cases, } \\
\mathrm{n}\end{array}$} & \multicolumn{4}{|c|}{ c-MYC expression } & \multicolumn{4}{|c|}{ HMGA2 expression } \\
\hline & & $\begin{array}{l}\text { Positive, } \\
\text { n (\%) }\end{array}$ & $\begin{array}{l}\text { Negative, } \\
\text { n }(\%)\end{array}$ & $\chi^{2}$ & P-value & $\begin{array}{l}\text { Positive, } \\
\mathrm{n}(\%)\end{array}$ & $\begin{array}{l}\text { Negative, } \\
\mathrm{n}(\%)\end{array}$ & $\chi^{2}$ & P-value \\
\hline Age, years & & & & 0.296 & 0.587 & & & 0.219 & 0.639 \\
\hline$\leq 45$ & 37 & $19(51.4)$ & 18 (48.6) & & & $20(54.1)$ & 17 (45.9) & & \\
\hline$>45$ & 65 & $37(56.9)$ & $28(43.1)$ & & & $32(49.2)$ & $33(50.8)$ & & \\
\hline Sex & & & & 0.548 & 0.459 & & & 0.394 & 0.530 \\
\hline Male & 58 & $30(51.7)$ & $28(48.3)$ & & & $28(48.3)$ & $30(51.7)$ & & \\
\hline Female & 44 & $26(59.1)$ & $18(40.9)$ & & & $24(54.5)$ & $20(45.5)$ & & \\
\hline Differentiation & & & & 0.559 & 0.455 & & & 0.004 & 0.948 \\
\hline Moderately & 35 & $21(60.0)$ & $14(40.0)$ & & & $18(51.4)$ & 17 (48.6) & & \\
\hline Poorly & 67 & $35(52.2)$ & $32(47.8)$ & & & $34(50.7)$ & $33(49.3)$ & & \\
\hline Tumor size, $\mathrm{cm}$ & & & & 1.267 & 0.531 & & & 1.460 & 0.482 \\
\hline$\leq 3$ & 21 & $13(61.9)$ & $8(38.1)$ & & & $12(57.1)$ & $9(42.9)$ & & \\
\hline $3-5$ & 55 & $31(56.4)$ & $24(43.6)$ & & & $25(45.5)$ & $30(54.5)$ & & \\
\hline$>5$ & 26 & $12(46.2)$ & $14(53.8)$ & & & $15(57.7)$ & $11(42.3)$ & & \\
\hline Location & & & & 1.456 & 0.228 & & & 0.025 & 0.874 \\
\hline Head & 62 & $37(59.7)$ & $25(40.3)$ & & & $32(51.6)$ & $30(48.4)$ & & \\
\hline Body/tail & 40 & $19(47.5)$ & $21(52.5)$ & & & $20(50.0)$ & $20(50.0)$ & & \\
\hline Lymph node metastasis & & & & 14.324 & $<0.001$ & & & 16.342 & $<0.001$ \\
\hline No & 59 & $23(39.0)$ & $36(61.0)$ & & & $20(33.9)$ & $39(66.1)$ & & \\
\hline Yes & 43 & $33(76.7)$ & $10(23.3)$ & & & $32(74.4)$ & $11(25.6)$ & & \\
\hline Invasion & & & & 30.657 & $<0.001$ & & & 18.949 & $<0.001$ \\
\hline No & 49 & $13(26.5)$ & $36(73.5)$ & & & $14(28.6)$ & $35(71.4)$ & & \\
\hline Yes & 53 & $43(81.1)$ & $10(18.9)$ & & & $38(71.7)$ & $15(28.3)$ & & \\
\hline $\begin{array}{l}\text { Tumor node metastasis } \\
\text { stage }\end{array}$ & & & & 30.934 & $<0.001$ & & & 11.743 & 0.001 \\
\hline $\mathrm{T} 1+\mathrm{T} 2$ & 58 & $18(31.0)$ & $40(69.0)$ & & & $21(36.2)$ & $37(63.8)$ & & \\
\hline $\mathrm{T} 3+\mathrm{T} 4$ & 44 & $38(86.4)$ & $6(13.6)$ & & & $31(70.5)$ & $13(29.5)$ & & \\
\hline $\begin{array}{l}\text { Serum cancer antigen } \\
19-9, \mathrm{U} / \mathrm{ml}\end{array}$ & & & & 0.042 & 0.839 & & & 2.595 & 0.107 \\
\hline$\leq 37$ & 30 & $16(53.3)$ & $14(46.7)$ & & & $19(63.3)$ & $11(36.7)$ & & \\
\hline$>37$ & 72 & $40(55.6)$ & $32(44.4)$ & & & $33(45.8)$ & $39(54.2)$ & & \\
\hline
\end{tabular}

HMGA-2, high mobility group AT-hook 2.

stroma also lowers the concentration of chemotherapeutic agents in the tumor, confers chemoresistance and affects tumor metabolism (38). Other studies have identified heterogeneity in PDAC, as well as the presence of cancer stem cells, which may lead to primary resistance to chemotherapeutic drugs and may be a key factor for tumor recurrence $(39,40)$. These factors have led to the failure of PDAC to respond to most conventional chemotherapeutic drugs (13). Therefore, KRAS was once considered as a potential therapeutic target in PDAC. Unfortunately, there is no therapeutic intervention that can target the KRAS mutation that leads to activation and subsequently block the downstream pathways $(41,42)$. Epidermal growth factor receptor (EGFR) is a member of the ERBB receptor tyrosine kinase (TK) family. EGFR contains an extracellular N-terminal ligand-binding domain, a transmembrane region and a $\mathrm{C}$-terminal intracellular domain that includes the kinase domain and multiple phosphorylation sites (43). Several ligands, including EGF- $\alpha$, transforming growth factor (TGF)- and amphiregulin, can bind to EGFR, which can then homodimerize or heterodimerize with other ERBB receptors resulting in autophosphorylation of specific TK residues on the receptor (44-46). The EGFR pathway is associated with different cancer-associated cellular features, such as proliferation, adhesion, neoangiogenesis and apoptosis. The EGFR pathway activates nuclear transcription factors involved in tumor cell growth, invasion, transformation and survival (43). EGFR plays an important role in carcinogenesis, is upregulated in $30-89 \%$ of PDACs and tends to predict poor 

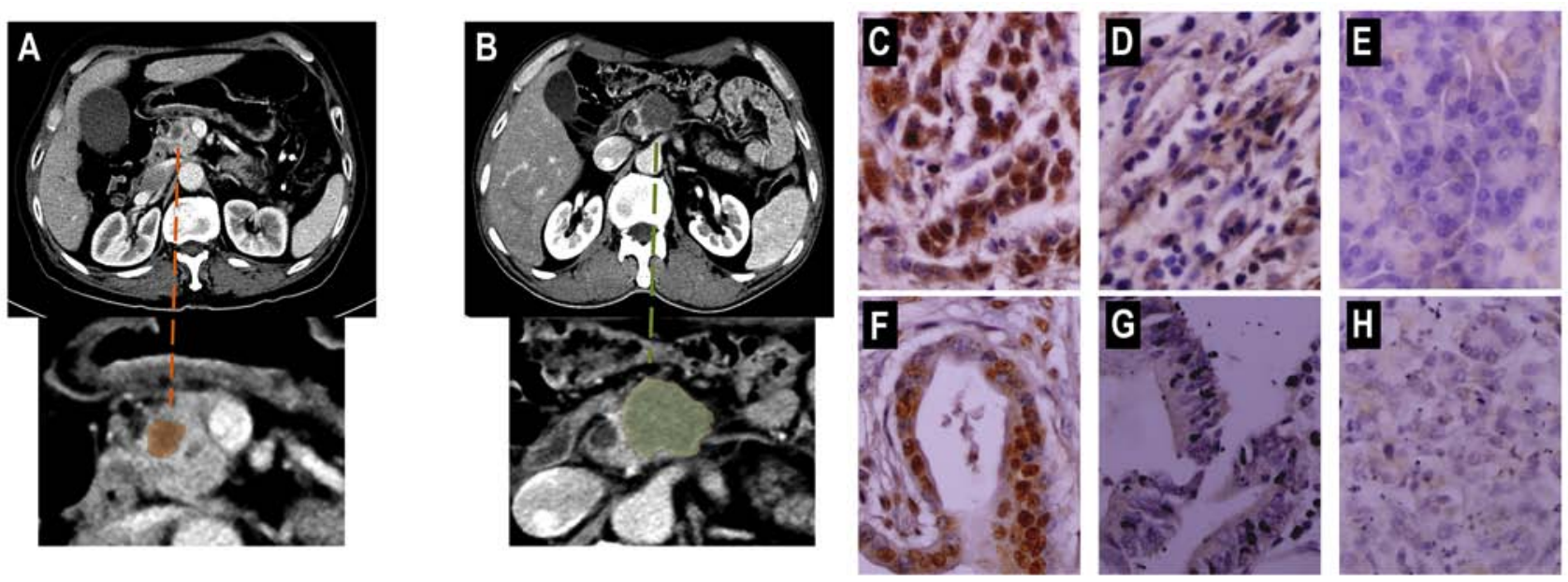

Figure 2. Representative preoperative CT images of patients with PDAC and immunohistochemical staining of PDAC tissues. (A) Axial venous phase images showing a tumor in the head of the pancreas with a maximum diameter of $1.0 \mathrm{~cm}$. (B) Axial venous phase images showing a tumor in the body of the pancreas with a maximum diameter of $3.2 \mathrm{~cm}$. (C) Positive c-MYC expression in PDAC. (D) Negative c-MYC expression in PDAC. (E) Negative c-MYC expression in peritumoral tissue. (F) Positive HMGA2 expression in PDAC. (G) Negative HMGA2 expression in PDAC. (H) Negative HMGA2 expression in peritumoral tissue. HMGA-2, high mobility group AT-hook 2; PDAC, pancreatic ductal adenocarcinoma.

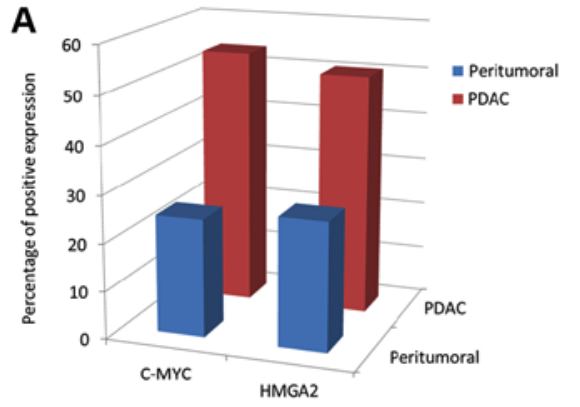

B
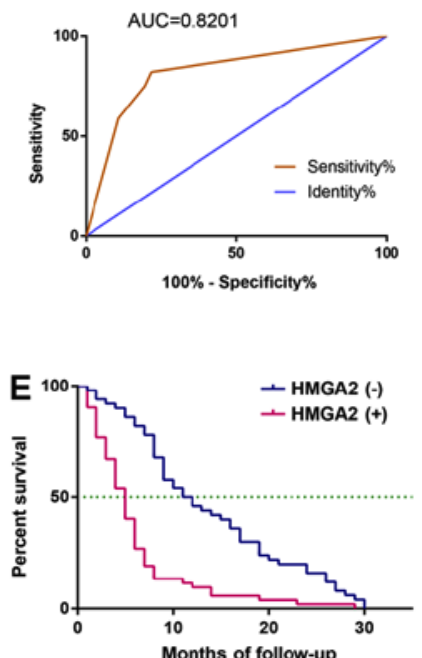

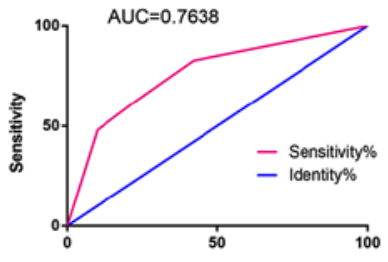

$100 \%$ - Specificity\%

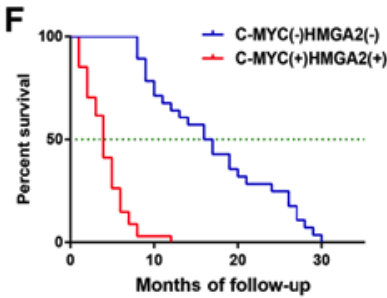

Figure 3. Expression analysis of c-MYC and HMGA2. (A) Comparison of expression of c-MYC and HMGA2 in PDAC and peritumoral tissues. (B) ROC curves of logistic regression models derived from clinicopathological characteristics for prediction of c-MYC expression. (C) ROC curves for predicting HMGA2 expression. Kaplan-Meier plots of overall survival in patients with PDAC with (D) positive and negative c-MYC expression; (E) positive and negative HMGA2 expression; and (F) positive or negative c-MYC and HMGA2 expression. HMGA-2, high mobility group AT-hook 2; PDAC, pancreatic ductal adenocarcinoma; ROC, receiver operating characteristic.

prognosis for patients (44). In view of this, therapeutic targeting of EGFR seems to be a promising strategy, however, so far results have not been optimistic A clinical trial demonstrated that patients receiving erlotinib plus gemcitabine had a median survival time of 6.24 months compared with 5.91 months in the gemcitabine plus placebo arm, with an absolute difference in median survival time $<1$ month (47). This may be due to induction of EGFR-independent tumor-induced angiogenesis, activation of alternative TK receptors that bypass the EGFR signaling pathway, mutations in EGFR or loss of the target, or many other resistance mechanisms to EGFR inhibitors (48). New targets are urgently needed to guide clinical treatment. The present study demonstrated that c-MYC and HMGA2 upregulation are significantly associated with progression and prognosis of PDAC.

c-MYC is a proto-oncogene that encodes a nuclear transcription factor, c-MYC protein regulates expression of many genes involved in cell cycle progression and cell growth, and drives the cell cycle by promoting progression from $\mathrm{G} 1$ to $\mathrm{S}$ phase and G2 to M phase $(49,50)$. c-MYC protein expression and gene activation by amplification have been described in a wide variety of malignancies and tend to predict poor prognosis, especially in lymphoma $(21,22,50)$. Other studies have shown that c-MYC plays an important role in the aggressiveness of PDAC $(18,51)$. The present study demonstrated that the rate of positive c-MYC expression was significantly higher in 
Table II. Logistic regression models of clinicopathological characteristics for c-MYC and HMGA2 expression.

\begin{tabular}{|c|c|c|c|c|}
\hline Gene & Covariate & OR & $95 \% \mathrm{CI}$ & P-value \\
\hline \multirow[t]{2}{*}{ c-MYC } & Tumor node metastasis stage & 5.097 & $1.546-16.805$ & 0.007 \\
\hline & Invasion & 5.249 & $1.734-15.886$ & 0.003 \\
\hline \multirow[t]{2}{*}{ HMGA2 } & Lymph node metastasis & 4.147 & $1.653-10.407$ & 0.002 \\
\hline & Invasion & 3.811 & $1.556-9.336$ & 0.03 \\
\hline
\end{tabular}

CI, confidence interval; HMGA-2, high mobility group AT-hook 2; OR, odds ratio; PDAC, pancreatic ductal adenocarcinoma.

Table III. Univariate analysis of factors affecting the survival of patients with pancreatic ductal adenocarcinoma.

\begin{tabular}{|c|c|c|c|c|c|}
\hline Variable & Cases, $\mathrm{n}$ & Mean survival, months & $95 \% \mathrm{CI}$ & $\chi^{2}$ & P-value \\
\hline Age, years & & & & 0.088 & 0.766 \\
\hline$\leq 45$ & 37 & 9.730 & $7.149-12.310$ & & \\
\hline$>45$ & 65 & 9.938 & 7.981-11.896 & & \\
\hline Sex & & & & 0.314 & 0.575 \\
\hline Male & 58 & 10.276 & $8.199-12.353$ & & \\
\hline Female & 44 & 9.318 & $6.966-11.671$ & & \\
\hline Differentiation & & & & 0.450 & 0.502 \\
\hline Moderately & 35 & 10.257 & $7.353-13.161$ & & \\
\hline Poorly & 67 & 9.657 & $7.830-11.483$ & & \\
\hline Tumor size, $\mathrm{cm}$ & & & & 0.060 & 0.970 \\
\hline$\leq 3$ & 21 & 10.143 & $6.620-13.665$ & & \\
\hline $3-5$ & 55 & 9.691 & $7.629-11.752$ & & \\
\hline$>5$ & 26 & 10.000 & $6.726-13.274$ & & \\
\hline Location & & & & 0.090 & 0.764 \\
\hline Head & 62 & 9.952 & $7.879-12.025$ & & \\
\hline Body/tail & 40 & 9.725 & $7.383-12.067$ & & \\
\hline Lymph node metastasis & & & & 26.098 & $<0.001$ \\
\hline No & 59 & 12.847 & $10.783-14.912$ & & \\
\hline Yes & 43 & 5.767 & $4.031-7.504$ & & \\
\hline Invasion & & & & 21.314 & $<0.001$ \\
\hline No & 49 & 13.633 & $11.318-15.948$ & & \\
\hline Yes & 53 & 6.377 & $4.777-7.978$ & & \\
\hline Tumor node metastasis stage & & & & 35.606 & $<0.001$ \\
\hline $\mathrm{T} 1+\mathrm{T} 2$ & 58 & 13.276 & $11.115-15.437$ & & \\
\hline $\mathrm{T} 3+\mathrm{T} 4$ & 44 & 5.364 & $4.031-6.696$ & & \\
\hline Serum cancer antigen $19-9, \mathrm{U} / \mathrm{ml}$ & & & & 0.269 & 0.604 \\
\hline$\leq 37$ & 30 & 10.867 & $7.940-13.793$ & & \\
\hline$>37$ & 72 & 9.444 & $7.610-11.279$ & & \\
\hline c-MYC & & & & 24.063 & $<0.001$ \\
\hline Negative & 46 & 14.196 & $11.778-16.613$ & & \\
\hline Positive & 56 & 6.304 & $4.831-7.776$ & & \\
\hline HMGA2 & & & & 28.618 & $<0.001$ \\
\hline Negative & 50 & 13.860 & $11.556-16.164$ & & \\
\hline Positive & 52 & 6.019 & $4.541-7.498$ & & \\
\hline
\end{tabular}

HMGA-2, high mobility group AT-hook 2.

PDAC compared with peritumoral tissues. In PDAC, positive c-MYC expression was significantly associated with lymph node metastasis, invasion to surrounding tissues and organs, and high TNM stage. Patients with PDAC who had positive 
Table IV. Multivariate Cox regression analysis to identify factors influencing the survival of with pancreatic ductal adenocarcinoma.

\begin{tabular}{lcccccc}
\hline Variable & $\mathrm{B}$ & $\mathrm{SE}$ & Wald & P-value & RR & $95 \%$ CI \\
\hline Tumor node metastasis stage & 0.645 & 0.262 & 6.032 & 0.014 & 1.905 & $1.139-3.186$ \\
Lymph node metastasis & 0.490 & 0.229 & 4.593 & 0.032 & 1.632 & $1.043-2.555$ \\
c-MYC & 0.586 & 0.250 & 5.489 & 0.019 & 1.797 & $1.101-2.934$ \\
HMGA2 & 0.910 & 0.225 & 16.321 & $<0.001$ & 2.486 & $1.598-3.866$ \\
\hline
\end{tabular}

CI, confidence interval; HMGA-2, high mobility group AT-hook 2; PDAC, pancreatic ductal adenocarcinoma; B, partial regression coefficient; $\mathrm{SE}$, standard error; Wald, wald value; RR, risk ratio.

c-MYC expression had a shorter OS time compared with patients who had negative c-MYC expression.

HMGA2 is a non-histone protein that acts as a transcription factor by altering chromatin architecture to regulate gene transcription $(52,53)$. A previous study has shown that HMGA2 protein plays a role in malignant cell transformation and the progression of several tumor types, and is associated with poor prognosis (54). Another study demonstrated that HMGA2 may be a direct transcriptional target of TGF- $\beta$, and may influence epithelial-mesenchymal transition and participate in tumor invasion and metastasis (55). Several studies have shown that HMGA2 has oncogenic activity, and can enhance the self-renewal capability of tumor stem cells and promote tumorigenesis $(56,57)$. Another study has shown that HMGA2 upregulation is significantly associated with tumor dedifferentiation (58). Previous studies on HMGA2 expression and PDAC have shown that HMGA2 upregulation is associated with poor tumor differentiation, lymph node metastasis and invasion $(34,58)$. The present study demonstrated that the rate of positive HMGA2 expression in PDAC tissues was significantly higher compared with peritumoral tissues. HMGA2 expression was not associated with tumor differentiation, but positive expression was significantly associated with lymph node metastasis, tumor invasion and high TNM stage. Patients with PDAC who had positive HMGA2 expression had shorter survival times compared with patients who had negative HGMA2 expression.

The current study systematically analyzed the association between the expression of c-MYC and HMGA2 in PDAC and peritumoral tissues and clinicopathological features and prognosis of patients with PDAC. Protein expression of c-MYC was positively correlated with HMGA2 expression $(\mathrm{P}=0.030)$. HMGA2 and c-MYC were found to be independent predictive factors of prognosis in patients with $\mathrm{PDAC}$, and positive expression of c-MYC and HMGA2 were significantly associated with lymph node metastasis, tumor invasion, high TNM stage and poor prognosis. The findings of the present study highlight the synergistic effects of c-MYC and HMGA2. Previous studies have shown that bromodomain and extraterminal domain protein inhibitors repress both c-MYC and HMGA2, affecting the growth of pancreatic cancer cells $(59,60)$, which is consistent with the findings of the present study. In addition, multiple regression analysis revealed that TNM stage and invasion were independent predictors of c-MYC expression, and lymph node metastasis and invasion were independent predictors of HMGA2 expression.
The present study had some limitations. Firstly, the sample size was small and there were no cases of well-differentiated adenocarcinoma, which could have affected the results. Secondly, the possible synergistic effect between c-MYC and HMGA2 expression was not thoroughly investigated. Thirdly, this study only considered c-MYC and HMGA2 protein expression at the immunohistochemical level and did not investigate mRNA expression. These limitations should be addressed in future studies.

In summary, expression of c-MYC and HMGA2 maybe important predictive factors for the prognosis of patients with PDAC. c-MYC and HMGA2 may be useful biomarkers and potential therapeutic targets in PDAC.

\section{Acknowledgements}

Not applicable.

\section{Funding}

The present study was supported by grants from the National Key Research and Development plan of China (nos. 2016YFC1100501 and 2016YFC0103100), the National Natural Science Foundation of China (no. 61701506) and The Science and Technology Innovation Program of Social Undertakings and People's Livelihood Security of Chongqing Science and Technology Commission (no. cstc2016shms-ztzx10002).

\section{Availability of data and materials}

The datasets used and/or analyzed during the present study are available from the corresponding author on reasonable request.

\section{Authors' contributions}

$\mathrm{KL}$ and JY were major contributors in writing the manuscript and analyzing the patient data. JC, YS, ZZ and WC made substantial contributions to study design, data analysis and interpretation and manuscript organization. All authors read and approved the final manuscript.

\section{Ethics approval and consent to participate}

This study was approved by the Human Ethics Committee of the Army Medical University (Chongqing, China) (approval 
no. KY201802). All information is stored in the databases of the First Affiliated Hospital of Army Medical University and utilized for research purposes. Oral consent was obtained from the family members of the patients included in the study. The ethics committee waived the requirement for further written informed consent for this study.

\section{Patient consent for publication}

Not applicable.

\section{Competing interests}

The authors declare that they have no competing interests.

\section{References}

1. Mostafa ME, Erbarut-Seven I, Pehlivanoglu B and Adsay V: Pathologic classification of 'pancreatic cancers': Current concepts and challenges. Chin Clin Oncol 6: 59, 2017.

2. Moyer MT and Gaffney RR: Pancreatic adenocarcinoma. N Engl J Med 371: 2140, 2014.

3. Siegel RL, Miller KD and Jemal A: Cancer statistics, 2015. CA Cancer J Clin 65: 5-29, 2015.

4. Bukki J: Pancreatic adenocarcinoma. N Engl J Med 371: 2139-2140, 2014.

5. Kuhlmann KF, de Castro SM, Wesseling JG, ten Kate FJ, Offerhaus GJ, Busch OR, van Gulik TM, Obertop H and Gouma DJ: Surgical treatment of pancreatic adenocarcinoma; actual survival and prognostic factors in 343 patients. Eur J Cancer 40: 549-558, 2004.

6. Parker SL, Tong T, Bolden S and Wingo PA: Cancer statistics, 1997. CA Cancer J Clin 47: 5-27, 1997.

7. Seufferlein T, Porzner M, Becker T, Budach V, Ceyhan G, Esposito I, Fietkau R, Follmann M, Friess H, Galle P, et al: S3-guideline exocrine pancreatic cancer. Z Gastroenterol 51: 1395-1440, 2013 (In German).

8. Erkan M, Michalski CW, Rieder S, Reiser-Erkan C, Abiatari I, Kolb A, Giese NA, Esposito I, Friess H and Kleeff J: The activated stroma index is a novel and independent prognostic marker in pancreatic ductal adenocarcinoma. Clin Gastroenterol Hepatol 6: 1155-1161, 2008.

9. Hidalgo M: Pancreatic cancer. N Engl J Med 362: 1605-1617, 2010.

10. Erkan M, Adler G, Apte MV, Bachem MG, Buchholz M, Detlefsen S, Esposito I, Friess H, Gress TM, Habisch HJ, et al: StellaTUM: Current consensus and discussion on pancreatic stellate cell research. Gut 61: 172-178, 2012.

11. Apte MV, Park S, Phillips PA, Santucci N, Goldstein D, Kumar RK, Ramm GA, Buchler M, Friess H, McCarroll JA, et al: Desmoplastic reaction in pancreatic cancer: Role of pancreatic stellate cells. Pancreas 29: 179-187, 2004.

12. Bochet L, Lehuede C, Dauvillier S, Wang YY, Dirat B, Laurent V, Dray C, Guiet R, Maridonneau-Parini I, Le Gonidec S, et al: Adipocyte-derived fibroblasts promote tumor progression and contribute to the desmoplastic reaction in breast cancer. Cancer Res 73: 5657-5668, 2013

13. Von Hoff DD, Ervin T, Arena FP, Chiorean EG, Infante J, Moore M, Seay T, Tjulandin SA, Ma WW, Saleh MN, et al: Increased survival in pancreatic cancer with nab-paclitaxel plus gemcitabine. N Engl J Med 369: 1691-1703, 2013.

14. Xiao AY, Tan ML, Wu LM, Asrani VM, Windsor JA, Yadav D and Petrov MS: Global incidence and mortality of pancreatic diseases: A systematic review, meta-analysis, and meta-regression of population-based cohort studies. Lancet Gastroenterol Hepatol 1: 45-55, 2016.

15. Siegel RL, Miller KD and Jemal A: Cancer statistics, 2017. CA Cancer J Clin 67: 7-30, 2017.

16. Berlin JD, Catalano P, Thomas JP, Kugler JW, Haller DG and Benson AB III: Phase III study of gemcitabine in combination with fluorouracil versus gemcitabine alone in patients with advanced pancreatic carcinoma: Eastern Cooperative Oncology Group Trial E2297. J Clin Oncol 20: 3270-3275, 2002.
17. Rocha Lima CM, Green MR, Rotche R, Miller WH Jr, Jeffrey GM, Cisar LA, Morganti A, Orlando N, Gruia G and Miller LL: Irinotecan plus gemcitabine results in no survival advantage compared with gemcitabine monotherapy in patients with locally advanced or metastatic pancreatic cancer despite increased tumor response rate. J Clin Oncol 22: 3776-3783, 2004.

18. Hessmann E, Schneider G, Ellenrieder V and Siveke JT: MYC in pancreatic cancer: Novel mechanistic insights and their translation into therapeutic strategies. Oncogene 35: 1609-1618, 2016.

19. Sears RC: The life cycle of C-MYC: From synthesis to degradation. Cell Cycle 3: 1133-1137, 2004.

20. Dang CV, O'Donnell KA, Zeller KI, Nguyen T, Osthus RC and Li F: The c-MYC target gene network. Semin Cancer Biol 16: 253-264, 2006.

21. Slack GW and Gascoyne RD: MYC and aggressive B-cell lymphomas. Adv Anat Pathol 18: 219-228, 2011.

22. Dalla-Favera R, Bregni M, Erikson J, Patterson D, Gallo RC and Croce CM: Human c-MYC onc gene is located on the region of chromosome 8 that is translocated in Burkitt lymphoma cells. Proc Natl Acad Sci USA 79: 7824-7827, 1982.

23. Sewastianik T, Prochorec-Sobieszek M, Chapuy B and Juszczynski P: MYC deregulation in lymphoid tumors: Molecular mechanisms, clinical consequences and therapeutic implications. Biochim Biophys Acta 1846: 457-467, 2014.

24. La Rosa S, Bernasconi B, Vanoli A, Sciarra A, Notohara K, Albarello L, Casnedi S, Billo P, Zhang L, Tibiletti MG and Sessa F: c-MYC amplification and c-myc protein expression in pancreatic acinar cell carcinomas. New insights into the molecular signature of these rare cancers. Virchows Arch 473: 435-441, 2018.

25. Johnson KR, Cook SA and Davisson MT: Chromosomal localization of the murine gene and two related sequences encoding high-mobility-group I and Y proteins. Genomics 12: 503-509, 1992.

26. Fusco A and Fedele M: Roles of HMGA proteins in cancer. Nat Rev Cancer 7: 899-910, 2007.

27. Reeves R and Nissen MS: The A.T-DNA-binding domain of mammalian high mobility group I chromosomal proteins. A novel peptide motif for recognizing DNA structure. J Biol Chem 265: 8573-8582, 1990.

28. Sgarra R, Zammitti S, Lo Sardo A, Maurizio E, Arnoldo L, Pegoraro S, Giancotti V and Manfioletti G: HMGA molecular network: From transcriptional regulation to chromatin remodeling. Biochim Biophys Acta 1799: 37-47, 2010.

29. Fedele M and Fusco A: HMGA and cancer. Biochim Biophys Acta 1799: 48-54, 2010.

30. $\mathrm{Wu} \mathrm{J}$ and Wei JJ: HMGA2 and high-grade serous ovarian carcinoma. J Mol Med (Berl) 91: 1155-1165, 2013.

31. Chiappetta G, Avantaggiato V, Visconti R, Fedele M, Battista S, Trapasso F, Merciai BM, Fidanza V, Giancotti V, Santoro M, et al: High level expression of the HMGI (Y) gene during embryonic development. Oncogene 13: 2439-2446, 1996.

32. Chang HY, Ye SP, Pan SL, Kuo TT, Liu BC, Chen YL and Huang TC: Overexpression of miR-194 reverses HMGA2-driven signatures in colorectal cancer. Theranostics 7: 3889-3900, 2017.

33. Hontecillas-Prieto L, Garcia-Dominguez DJ, Garcia-Mejias R, Ramirez-Villar GL, Saez C and de Alava E: HMGA2 overexpression predicts relapse susceptibility of blastemal Wilms tumor patients. Oncotarget 8: 115290-115303, 2017.

34. Hristov AC, Cope L, Reyes MD, Singh M, Iacobuzio-Donahue C, Maitra A and Resar LM: HMGA2 protein expression correlates with lymph node metastasis and increased tumor grade in pancreatic ductal adenocarcinoma. Mod Pathol 22: 43-49, 2009.

35. Allen PJ, Kuk D, Castillo CF, Basturk O, Wolfgang CL, Cameron JL, Lillemoe KD, Ferrone CR, Morales-Oyarvide V, He J, et al: Multi-institutional validation study of the American Joint Commission on Cancer (8th Edition) Changes for T and $\mathrm{N}$ Staging in patients with pancreatic adenocarcinoma. Ann Surg 265: 185-191, 2017.

36. Rieser CJ, Zenati M, Hamad A, Al Abbas AI, Bahary N, Zureikat AH, Zeh HJ III and Hogg ME: CA19-9 on postoperative surveillance in pancreatic ductal adenocarcinoma: Predicting recurrence and changing prognosis over time. Ann Surg Oncol 25: 3483-3491, 2018.

37. Chang HJ, Yoo BC, Kim SW, Lee BL and Kim WH: Significance of PML and p53 protein as molecular prognostic markers of gallbladder carcinomas. Pathol Oncol Res 13: 326-335, 2007. 
38. Erkan M, Reiser-Erkan C,Michalski CW, DeuckerS, Sauliunaite D, Streit S, Esposito I, Friess H and Kleeff J: Cancer-stellate cell interactions perpetuate the hypoxia-fibrosis cycle in pancreatic ductal adenocarcinoma. Neoplasia 11: 497-508, 2009.

39. Lonardo E, Frias-Aldeguer J, Hermann PC and Heeschen C: Pancreatic stellate cells form a niche for cancer stem cells and promote their self-renewal and invasiveness. Cell Cycle 11: 1282-1290, 2012.

40. Van den Broeck A, Gremeaux L, Topal B and Vankelecom H: Human pancreatic adenocarcinoma contains a side population resistant to gemcitabine. BMC Cancer 12: 354, 2012.

41. Morris JP IV, Wang SC and Hebrok M: KRAS, Hedgehog, Wnt and the twisted developmental biology of pancreatic ductal adenocarcinoma. Nat Rev Cancer 10: 683-695, 2010.

42. Chung V, McDonough S, Philip PA, Cardin D, Wang-Gillam A, Hui L, Tejani MA, Seery TE, Dy IA, Al Baghdadi T, et al: Effect of Selumetinib and MK-2206 vs Oxaliplatin and fluorouracil in patients with metastatic pancreatic cancer after prior therapy: SWOG S1115 study randomized clinical trial. JAMA Oncol 3: 516-522, 2017.

43. Salomon DS, Brandt R, Ciardiello F and Normanno N: Epidermal growth factor-related peptides and their receptors in human malignancies. Crit Rev Oncol Hematol 19: 183-232, 1995.

44. Cohenuram M and Saif MW: Epidermal growth factor receptor inhibition strategies in pancreatic cancer: Past, present and the future. JOP 8: 4-15, 2007.

45. Ioannou N, Dalgleish AG, Seddon AM, Mackintosh D, Guertler U, Solca F and Modjtahedi H: Anti-tumour activity of afatinib, an irreversible ErbB family blocker, in human pancreatic tumour cells. Br J Cancer 105: 1554-1562, 2011.

46. Liles JS, Arnoletti JP, Kossenkov AV, Mikhaylina A, Frost AR, Kulesza P, Heslin MJ and Frolov A: Targeting ErbB3-mediated stromal-epithelial interactions in pancreatic ductal adenocarcinoma. Br J Cancer 105: 523-533, 2011.

47. Moore MJ, Goldstein D, Hamm J, Figer A, Hecht JR, Gallinger S, Au HJ, Murawa P, Walde D, Wolff RA, et al: Erlotinib plus gemcitabine compared with gemcitabine alone in patients with advanced pancreatic cancer: A phase III trial of the National Cancer Institute of Canada Clinical Trials Group. J Clin Oncol 25: 1960-1966, 2007.

48. Chua YJ and Zalcberg JR: Pancreatic cancer-is the wall crumbling? Ann Oncol 19: 1224-1230, 2008.
49. Dang CV: c-MYC target genes involved in cell growth, apoptosis, and metabolism. Mol Cell Biol 19: 1-11, 1999.

50. Xu J, Chen Y and Olopade OI: MYC and breast cancer. Genes Cancer 1: 629-640, 2010.

51. Nesbit CE, Tersak JM and Prochownik EV: MYC oncogenes and human neoplastic disease. Oncogene 18: 3004-3016, 1999.

52. Di Cello F, Hillion J, Hristov A, Wood LJ, Mukherjee M, Schuldenfrei A, Kowalski J, Bhattacharya R, Ashfaq R and Resar LM: HMGA2 participates in transformation in human lung cancer. Mol Cancer Res 6: 743-750, 2008.

53. Ozturk N, Singh I, Mehta A, Braun T and Barreto G: HMGA proteins as modulators of chromatin structure during transcriptional activation. Front Cell Dev Biol 2: 5, 2014.

54. Pallante P, Sepe R, Puca F and Fusco A: High mobility group a proteins as tumor markers. Front Med (Lausanne) 2: 15, 2015.

55. Thuault S, Valcourt U, Petersen M, Manfioletti G, Heldin CH and Moustakas A: Transforming growth factor-beta employs HMGA2 to elicit epithelial-mesenchymal transition. J Cell Biol 174: 175-183, 2006

56. Kaur H, Ali SZ, Huey L, Hütt-Cabezas M, Taylor I, Mao XG, Weingart M, Chu Q, Rodriguez FJ, Eberhart CG and Raabe EH: The transcriptional modulator HMGA2 promotes stemness and tumorigenicity in glioblastoma. Cancer Lett 377: 55-64, 2016.

57. Madison BB, Jeganathan AN, Mizuno R, Winslow MM, Castells A, Cuatrecasas M and Rustgi AK: Let-7 represses carcinogenesis and a stem cell phenotype in the intestine via regulation of Hmga2. PLoS Genet 11: e1005408, 2015.

58. Piscuoglio S, Zlobec I, Pallante P, Sepe R, Esposito F, Zimmermann A, Diamantis I, Terracciano L, Fusco A and Karamitopoulou E: HMGA1 and HMGA2 protein expression correlates with advanced tumour grade and lymph node metastasis in pancreatic adenocarcinoma. Histopathology 60: 397-404, 2012.

59. Sahai V, Kumar K, Knab LM, Chow CR, Raza SS, Bentrem DJ, Ebine K and Munshi HG: BET bromodomain inhibitors block growth of pancreatic cancer cells in three-dimensional collagen. Mol Cancer Ther 13: 1907-1917, 2014.

60. Dangi-Garimella S, Sahai V, Ebine K, Kumar K and Munshi HG: Three-dimensional collagen I promotes gemcitabine resistance in vitro in pancreatic cancer cells through HMGA2-dependent histone acetyltransferase expression. PLoS One 8: e64566, 2013. 